\title{
Dynamics of Circular Debt in Pakistan and Its Resolution
}

\author{
Syed Sajid Ali ${ }^{*}$ and Sadia Badar ${ }^{* *}$
}

\begin{abstract}
This paper examines the circular debt problem in the Pakistani energy sector. After presenting the profile of the energy sector in Pakistan, the paper explains why circular debt has emerged in the sector. Two principal reasons are discussed for the circular debt problem: First, consumer tariffs were insufficient to recover the rising costs of power generation and the government (due to fiscal constraints) was not compensating PEPCO for the resulting losses. Second, PEPCO has faced significant problems in recovering dues from consumers. In order to resolve the circular debt problem, sharp adjustments in power tariffs may be required combined with the need by the government to explicitly recognize the costs of power subsidies in the budget.
\end{abstract}

Keywords: Circular debt, energy, tariff, subsidy, Pakistan.

JEL Classification: H62, Q48, Q43.

\section{Introduction}

Circular debt occurs when one entity facing problems in its cash inflows holds back payments to its suppliers and creditors. Thus, problems in the cash inflow of one entity cascade down to other segments of the payment chain. In Pakistan, the energy sector has faced this issue for several years. This has several implications for the economy, for example:

- The resulting cash flow constraints have added to the operational inefficiencies of companies in the power sector. In some cases, power generation companies are operating below their capacity due to liquidity constraints.

\footnotetext{
* Additional Director, Policy Research Department, The State Bank of Pakistan. The views expressed in the paper are those of the authors and do not necessarily reflect those of the State Bank of Pakistan.

** Joint Director, Monetary Policy Department, The State Bank of Pakistan.
} 
- The consequent increase in the power supply deficit has also contributed to supply-side constraints. Thus, it can be argued that the buildup of circular debt has led to a reduction in the potential gross domestic product (GDP) of the country. If this is true, any policy stimulus to growth could be less effective in terms of achieving the desired results.

- The build-up of circular debt has led banks to accumulate alarmingly high exposures on the energy sector-outstanding credit to Pepco, independent power producers (IPPs) and Shell (oil marketing company [OMC]) stood at just over Rs485 billion at end-December 2009. To put this in perspective, banks' outstanding credit to the textile sector-the largest industrial sector of the country-was Rs535 billion at end-December 2009.

The objective of this paper is to explain the circular debt issue and evaluate various policy options for its resolution. Section 2 develops a basic understanding of circular debt. Section 3 identifies the underlying reasons for the buildup of circular debt in the energy sector, and policy options to resolve circular debt have been analyzed in Section 4. The paper concludes with a summary of key observations in Section 5.

\section{Understanding Circular Debt in the Energy Sector}

To better understand circular debt, it is pertinent to briefly review the profile of the energy sector in Pakistan. As illustrated in Chart 1, the following are key players in the energy sector:

(i) Suppliers of primary energy: These include (a) oil/gas exploration companies (e.g., OGDCL and PPL), (b) oil refineries (e.g., ARL, Parco), and (c) distribution companies in gas (e.g., SNGPL, SSGC) and oil (e.g., PSO, Shel1). All companies in this segment are involved in the supply of primary energy to power generation companies.

(ii) Power generation and distribution companies: These comprise the Karachi Electric Supply Company (KESC) (a vertically integrated company), Independent Power Producers (IPPs) (e.g., Hub Power Company and Kot Addu Power Company), captive power producers, rental power producers, WAPDA Hyde1, and the Pakistan Electric Power Company (PEPCO). PEPCO is the core entity in the energy sector. It is an umbrella institution managing power generation companies (GENCOs), the National Transmission and Despatch Company (NTDC), and power distribution companies 
(DISCOs). ${ }^{1}$ Approximately 90 percent of the power generation in the country falls under PEPCO's area of influence.

Chart-1: Key Players in the Energy Sector

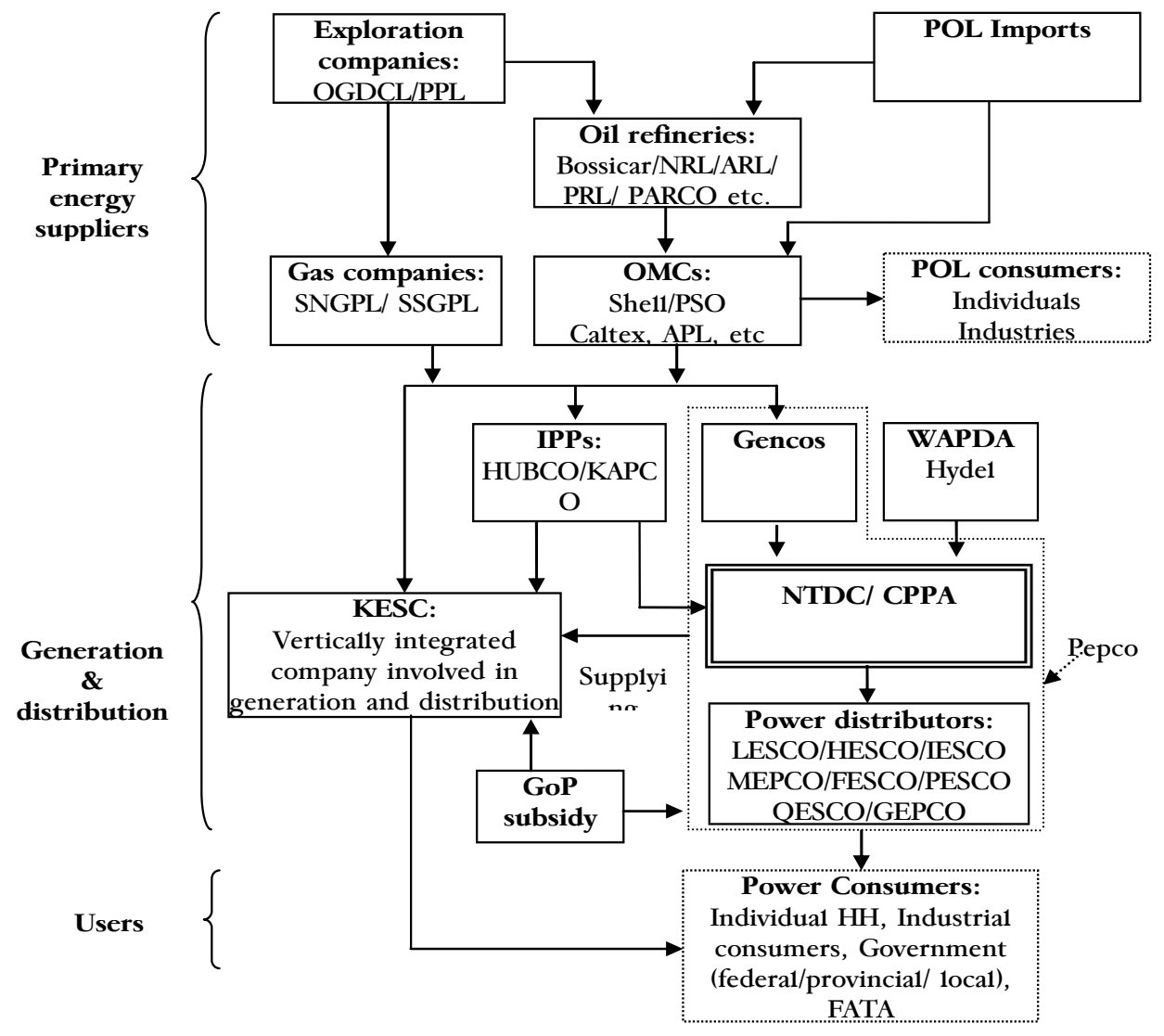

Power consumers: These include individuals, industries, and the government sector as a user. It may be noted that tariffs paid by power consumers (often subsidized by the government) are used to make payments at various stages of the energy supply chain (i.e., power generation and distribution companies and suppliers of primary energy).

The circular debt in the energy sector is closely related to cash flow problems in PEPCO. Since PEPCO is the core entity in the energy sector

\footnotetext{
${ }^{1}$ As a part of overall energy sector reforms, the Water the Power Development Authority (WAPDA) was restructured into 14 different entities: four thermal power generation companies (GENCOs), one company managing the transmission of power (NTDC), and nine companies (DISCOs) responsible for the distribution of power to consumers. Pepco managed this unbundling process and is currently the holding company for these entities.
} 
and manages the financial flows of all entities under its control, ${ }^{2}$ any problem in PEPCO cash flows is transmitted to other segments of the energy supply chain.

As shown in Table-1, PEPCO collects tariffs from its customers for the supply of electricity (and tariff subsidies from the government), ${ }^{3}$ and pays suppliers (IPPs, OMCs, and gas companies) for the procurement of power and fuel. For smooth functioning, PEPCO's tariff collection should be sufficient to meet the cost of energy supply, i.e., inflows should meet outflows. ${ }^{4}$ But this is not as simple for PEPCO: outflows are certain as these are contractual in nature whereas inflows are uncertain (absence or delays in tariff payments). This means that inflows always lag behind outflows. In other words, there is a basic imbalance in PEPCO's cash flows.

Like any other company, PEPCO has options to (a) use its own cash reserves, (b) avail financing, or (c) increase payables (avail suppliers' credit). In a normal situation, PEPCO maintains a certain volume of payables as a part of its cash management strategy. However, 2008/09 was difficult year because payment obligations increased due to rising oil prices in the international market and inflows declined as the government (and its various departments) fell short on their payments. The liquidity constraints for PEPCO were compounded because its consumers were not fully paying their power tariffs.

Table-1: Stylized Cash Flows of PEPCO

\begin{tabular}{ll}
\hline Inflows & Outflows \\
\hline Tariff collected from & Payment to suppliers \\
Government (as consumer) & OMCs \\
Private sector (as consumer) & Gas companies \\
KESC (as consumer) & Power producers \\
GoP subsidy on tariffs & \\
\hline
\end{tabular}

${ }^{2}$ It may be noted that envisaged reforms in the power sector also required a separate entity, the Central Power Purchase Agency (CPPA), to act as a clearing agent for all trade in electricity. Though the government created the CPPA (a move toward creating a single buyer purchasing power from IPPs and GENCOs, and selling to DISCOs), this was set up under Pepco. As a result, Pepco continues to control the cash flows of all companies under its management.

3 This is because the government provides relief to power consumers by keeping electricity tariffs artificially low.

${ }^{4}$ Due to timing mismatches between cash outflows and cash inflows, companies generally maintain a certain proportion of their overall cash flows as a balance in 'transition.' 
Thus, the buildup of receivables eventually led PEPCO to delay (or suspend) payments to its suppliers. Payment arrears seeped into other segments of the energy supply chain, i.e., power generation companies (GENCOs, IPPs, WAPDA Hyde1), oil marketing companies (PSO, Shel1), gas distribution companies (SNGPL and SSGC), refineries (Parco, Bosicor, PRL, NRL), and oil and gas exploration companies (OGDCL, PPL) (see Chart 2).

\section{Chart-2: Payment Flow in the Energy Sector}

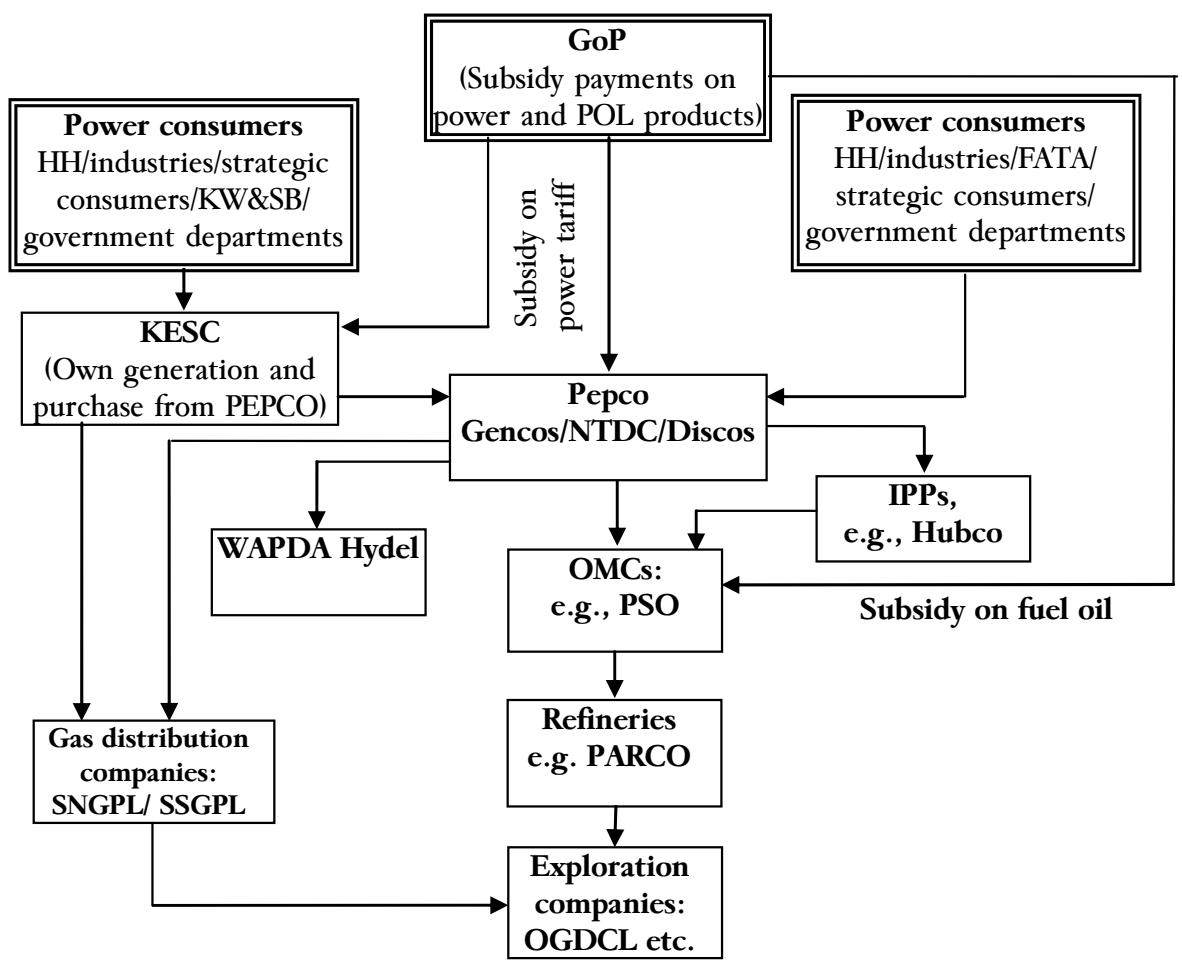

It may be noted that exploration companies and refineries used their own cash to finance the liquidity crunch since they stood at the very top of the energy supply chain. This in turn affected their expansion plans, which is likely to have adverse consequences for the country's ability to meet its energy needs when going forward.

Furthermore, PEPCO's receivables act as an envelope for the maximum stock of circular debt. The actual extent of circular debt may in

\footnotetext{
${ }^{5}$ To continue with their operations, some of the entities in energy supply chain may avail bank financing or use their own cash reserves so that they can meet their payment obligations.
} 
fact be moderated to the extent that entities in the energy supply chain can finance receivables from internal sources.

\section{Why did Circular Debt Emerge?}

There are two main reasons for the buildup of circular debt:

1. End-consumer tariffs were insufficient to recover the rising costs of power generation, and the government, due to fiscal constraints, was not fully compensating PEPCO against the resulting losses.

While all power tariffs are determined by the National Electric and Power Regulatory Authority (NEPRA), ${ }^{6}$ there is a difference in the way that tariff decisions are implemented for power generation companies and endconsumers.

Specifically, tariffs for power generation companies are governed by power purchase agreements, ${ }^{7}$ which define the base tariff for power generation as well as the process for subsequent adjustments (e.g., against rising fuel costs, inflation, exchange rate changes, etc.). Thus, tariff revisions are automatically reflected in power purchase prices. NEPRA only validates the cost claims of power suppliers.

In the case of end-consumers, although NEPRA determines their tariffs, the government has a key role as these tariffs become legally binding only after being notified by the government. This severely limits NEPRA's operational independence.

As a result of this weakness, we observed the following:

- During November 2003 to February 2007, end-consumer tariffs remained unchanged. This was because NEPRA did not allow any revision in tariffs despite requests from DISCOs.

- After February 2007, NEPRA allowed some upward revision in tariffs in response to the increase in the power purchase price. But the government-notified tariffs remained lower than those determined by NEPRA (see Figure 1). This reflects the government's reluctance to completely pass on the tariff increase to end-consumers. The difference

\footnotetext{
${ }^{6}$ Formally established in December 1997, NEPRA is responsible for determining tariffs for the supply of electric power by generation, transmission and distribution companies.

${ }^{7}$ These are agreements between power suppliers and power purchasers.
} 
between the tariff determined by NEPRA and finally notified by the government is the tariff differential subsidy paid to consumers.

Figure-1: Power Tariffs for Consumers

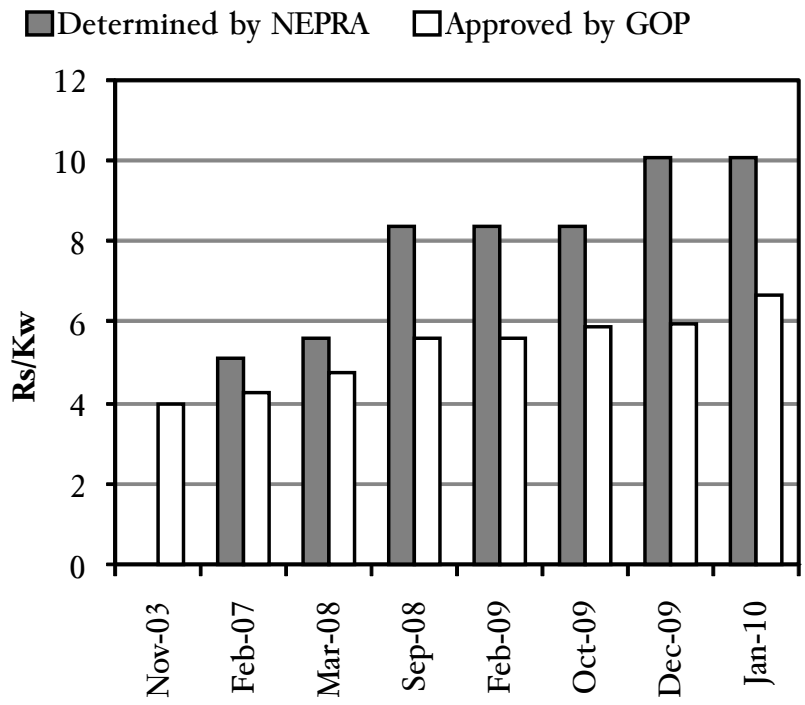

- On the other hand, tariffs for power suppliers (IPPs and GENCOs) continued to rise mainly due to rising fuel prices and the depreciating value of the rupee against the US dollar. As mentioned earlier, any adjustment in the power suppliers' tariff does not require government approval to be effective.

This means that end-consumer tariffs were insufficient to recover the rising costs of power generation. Figure 2 shows that the wedge between consumer tariffs and power purchase prices has been rising consistently. Since the government was not fully ${ }^{8}$ compensating PEPCO against these losses, this wedge essentially shows the extent of loss that PEPCO incurred on each unit of power it supplied. Furthermore, electricity generation kept on increasing during this period, which magnified the cash flow problem for PEPCO (see Figure 3).

\footnotetext{
${ }^{8}$ The government provides only the budgeted amount against tariff differential claims. Further, with growing fiscal constraints, the government was finding it difficult to settle PEPCO's claims on a timely basis.
} 
Figure-2: Consumer Tariff vis-a-vis Cost of Power Generation

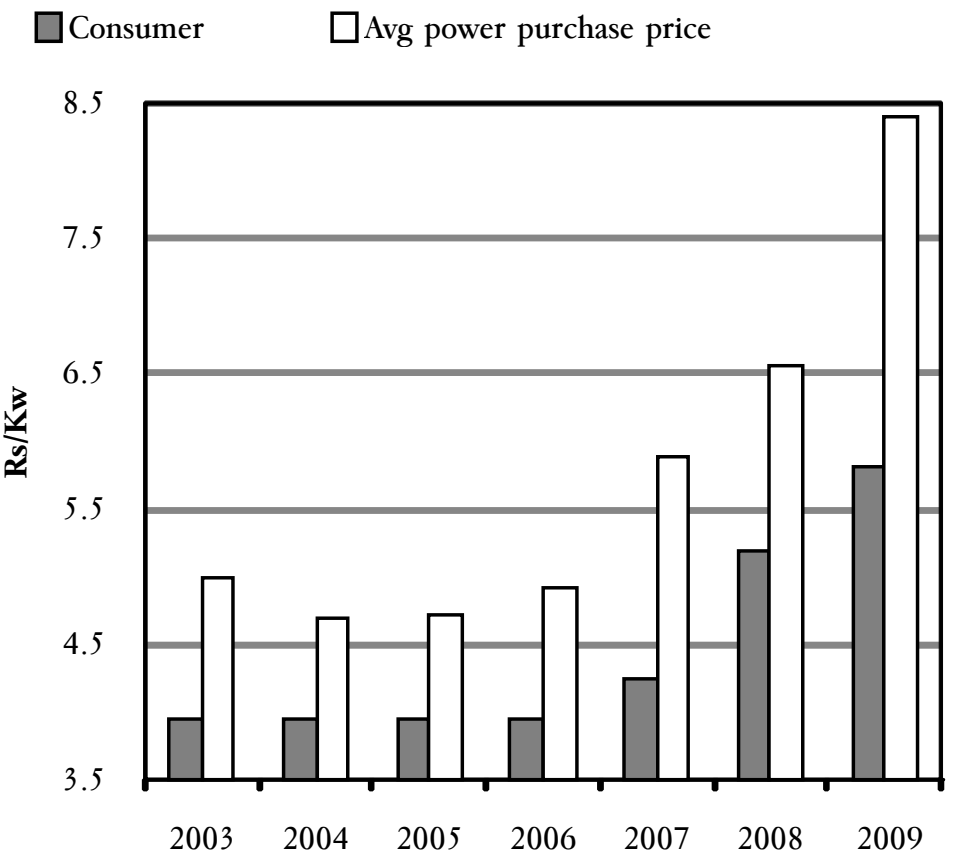

Figure-3: Total Generation of Electricity

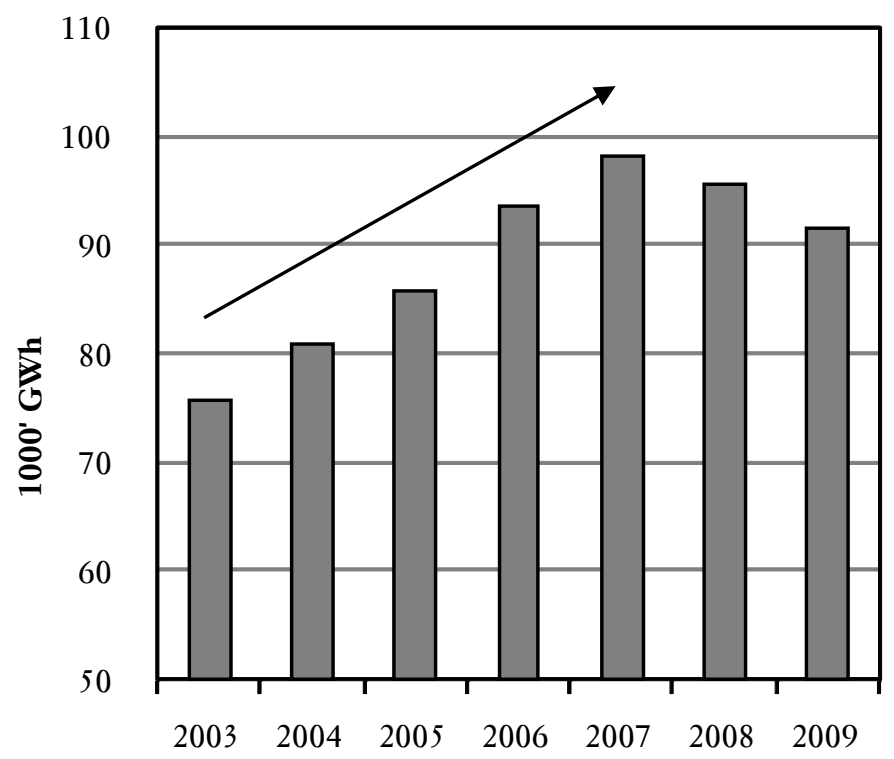




\section{PEPCO has also been facing problems in recovering dues from its consumers.}

Over time, PEPCO has developed significant dues from its consumers:

- Recovery of dues from FATA is very low. Similarly, a number of private individuals do not pay their monthly electricity bills.

- A number of departments in the federal and provincial governments have been delaying their payment of dues.

- There is a payment dispute between the KESC and PEPCO.

Figure 4 explains how these receivables built up over time. These receivables increased sharply from 2006 onward. ${ }^{10}$ A major part of this rise is explained by private consumers where PEPCO can be most effective in terms of recovery of dues. ${ }^{11}$ This is an enforcement issue as some DISCOs are unable to improve recovery of their electricity bills from private consumers.

In sum, PEPCO's cash flows have thus been strained, since (a) endconsumer tariffs were insufficient to recover the rising costs of power generation, and (b) the recovery of power tariffs was inadequate. In June 2006, PEPCO started borrowing from banks against government guarantees, mainly to compensate against the non-receipt of tariff subsidies from government-this is the point at which the circular debt issue emerged.

\footnotetext{
${ }^{9}$ The dispute emerged when PEPCOepco started billing the KESC on the basis of the marginal cost of power generation as opposed to the average uniform rate applicable to other DISCOs. Although the dispute was settled in April 2009, Pepco claims that KESC is falling short on its agreed payments.

10 The fall in total receivables during January 2010 was mainly due to the settlement of FATA claims worth Rs. 83 billion. This settlement was the outcome of a term finance certificate (TFC) issuance in September 2009. We will discuss this in more detail in the next position paper.

11 The rise in receivables from private consumers is in line with the upward revision in electricity tariffs.
} 
Figure-4: PEPCO’s Receivables

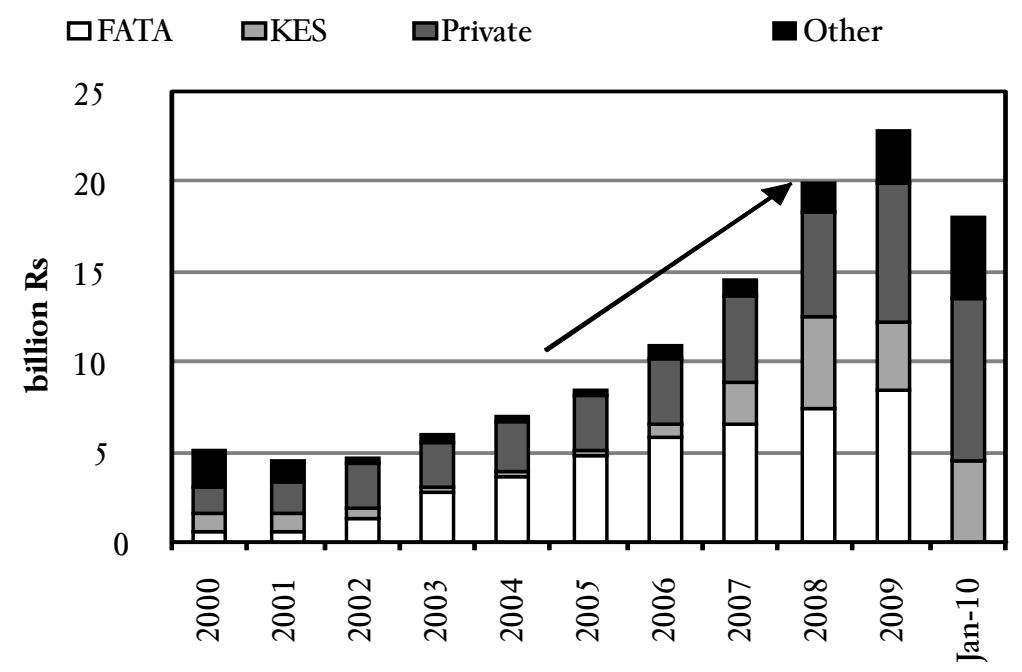

This was also when PEPCO started delaying payments to its suppliers. For example, in August 2006, PEPCO deferred its payments to IPPs initially for a few days, later extended to longer periods. ${ }^{12}$ As a result, IPPs began facing stress on their cash flows, which eventually forced them to borrow from the banking system in June 2007. In this way, problems in PEPCO's cash flows cascaded down to other segments of the energy supply chain (see Chart 3).

It may be noted that OMCs (e.g., PSO, Shell) were already facing a liquidity crunch in June 2007 as the government was delaying the settlement of price differential claims relating to fuel prices. ${ }^{13}$

Thus the cash flow problem that started from PEPCO has impacted all players in the energy sector. Although the government has taken a number of remedial measures, according to our estimates, the size of circular debt by mid-January 2010 was around Rs. 150 billion.

\footnotetext{
${ }^{12}$ We believe that PEPCO accords priority to oil and gas supply companies (over IPPs) while clearing payments to ensure that its own power generation capability remains intact.

${ }^{13}$ In order to insulate domestic consumers from the pass through of sharply rising oil prices in the international market, the government assumed the cost differential between global and domestic fuel prices; this differential, which was supposed to be paid to OMCs, remained outstanding.
} 
Chart 3: How Inter-corporate debt chain developed in the energy sector?

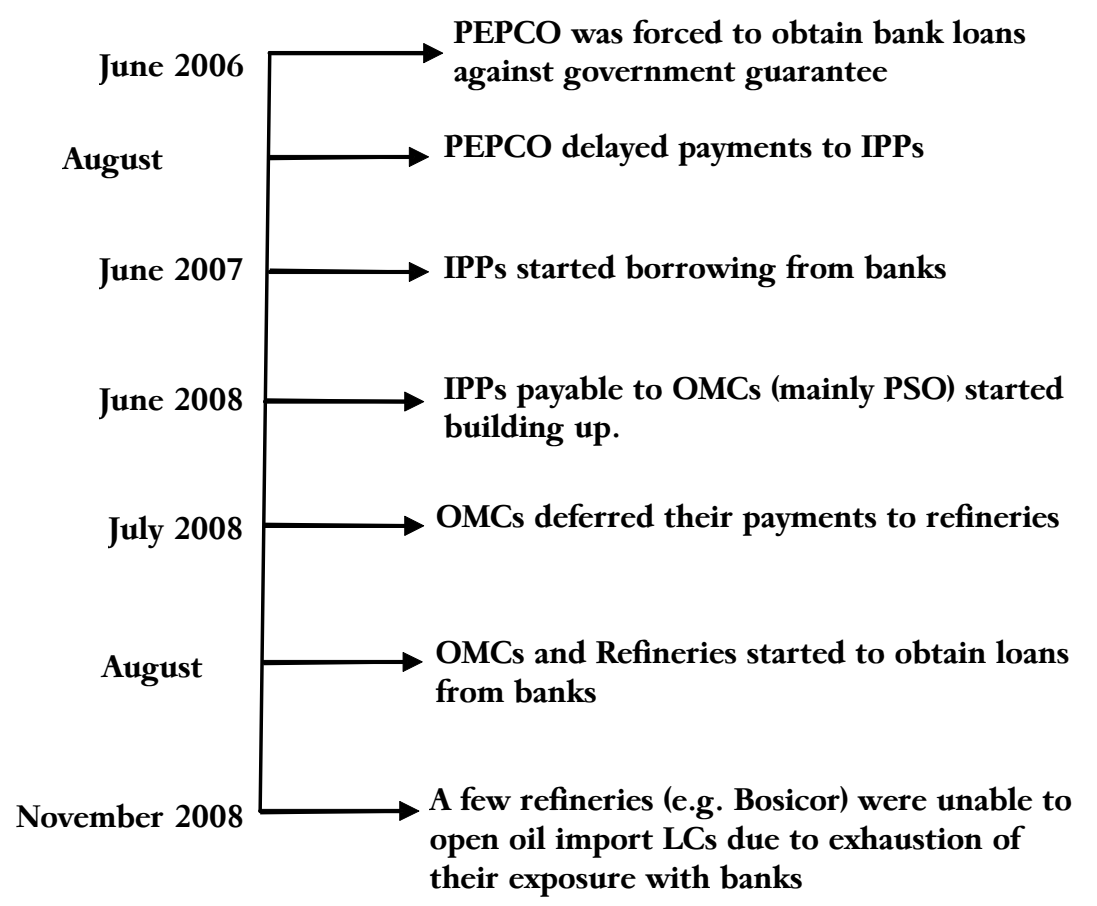

\section{Resolution of Circular Debt}

The strategy to resolve circular debt must focus not only on reducing the outstanding stock of circular debt but also on preventing its accumulation.

In order to reduce the outstanding stock of circular debt, the government created a power holding company in mid-2009. The purpose of this company was to acquire all debt created on PEPCO's balance sheet due to delays in its receipts.

As mentioned earlier, PEPCO had been borrowing from the banking system against government guarantees to offset the unpaid tariff subsidy claims. These bank borrowings were supplemented by the issuance of a term finance certificate (TFC) worth Rs. 80 billion in March 2009. Thus, by endMarch 2009, the debt burden for PEPCO reached over Rs. 200 billion, which was acquired by the power holding company. This acquisition meant that the government settled the unpaid subsidy claims accrued up until June 2009. The power holding company issued another TFC worth Rs. 85 billion in September 2009. The proceeds from this TFC issuance were used to settle FATA claims of over Rs. 80 billion. 
Since consumer tariffs have been insufficient to cover the cost of power generation (see Figure 2), further build-up of circular debt cannot be avoided without sharp upward adjustment in power tariffs. According to reports, by end-June 2009, an immediate 24 percent increase in tariffs was required to cover the generation cost. The government, however, decided to stagger this increase into three phases of 6 percent in October 2009, 12 percent in January 2010, and 6 percent in April 2010. This delay in tariff adjustment translates into an increase in cost for PEPCO. In order to cover this increase in cost, the government allocated Rs. 55 billion in the FY2010 budget as subsidy for the power sector. Moreover, the government is allowing monthly adjustments in power tariffs so that changes in fuel price are passed on to consumers in a timely manner.

Despite these measures, the problem of circular debt still lingers on. This is because power consumption is still subsidized ${ }^{14}$ and the government does not have the fiscal space to explicitly recognize the cost of this subsidy in the budget. ${ }^{15}$ Indeed, political concerns are making it more difficult for the government to completely remove power subsidies. Furthermore, the policy choice is becoming more challenging owing to the possible existence of a Laffer curve in the power sector. Specifically, given that consumers are reluctant to pay their bills, and this tendency is increasing, there is a risk that going forward to a marginal increase in tariffs may result in a decline in revenue collection for PEPCO (see Figure 5). ${ }^{16}$ The government would like to avoid this situation as this would reflect a complete breakdown of the social contract.

However, we must also understand that addressing the circular debt issue is important due to its adverse impacts on potential GDP. This is because liquidity constraints for entities in the energy sector have led to falls in power generation. As is evident from Figure 3, the decline in power generation in 2008 and 2009 is quite peculiar. We believe this is a manifestation of circular debt as power generation companies are managing their cash flows by reducing their output. This means that by addressing the circular debt issue, we can restore a part of this loss in power generation. In fact it can be argued that to the extent that the power unavailability has increased supply constraints for the economy, the

\footnotetext{
${ }^{14}$ In addition to fuel prices changes, there are other cost increases that need to be passed on (e.g., cost increase under O\&M component due to exchange rate changes or due to inflation) to consumers on quarterly basis. These quarterly adjustments are still pending.

${ }^{15}$ Stabilization program with the IMF limits government ability to continue with large subsidies to the power sector.

${ }^{16}$ Containing power theft requires not only strong enforcement but also large capital investments by PEPCO.
} 
output gap has become more stringent for any policy stimulus to promote economic growth.

\section{Conclusion}

The resolution of circular debt is necessary as this will ease supply constraints. The task is challenging since it requires the outstanding stock of circular debt to be cleared before plugging further build-up of circular debt receivables. One key lesson is that power subsidies can be sustained only if these are explicitly recognized in the fiscal budget; otherwise, the economy will continue to suffer from the indirect cost of these subsidies. 


\section{References}

Malik, A. (2007). Effectiveness of Regulatory Structure in the Power Sector of Pakistan. Working Paper Number 25 of Pakistan Development Institute.

Hathaway, R.M. et. a1. (2007). Fueling the Future: Meeting Pakistan's Energy Needs in the 21st Century. Woodrow Wilson: International Center for Scholars.

Ghafoor, A., and Weiss, J. (1999). Privatization of Electric Power Sector in Pakistan. Pakistan Development Review, 38:1.

Hydrocarbon Development Institute (2008). Pakistan Energy Yearbook 2008.

Hydrocarbon Development Institute (2009). Pakistan Energy Yearbook 2009.

Karachi Electric Supply Company (2009). Annual Report 2008-2009.

National Electric Power Regulatory Authority (2008). Annual Report 20072008.

National Electric Power Regulatory Authority (2008). State of Industry Report 2008.

National Electric Power Regulatory Authority (2009). State of Industry Report 2009.

USAID (2007). Energy Sector Assessment for USAID/Pakistan. 